\title{
Women's Health Education; Formal Training system of women in Iran before Mashrootiat Revolution till 1298 A.H. that the First School of Midwifery was Founded
}

\section{A R T I C L E I N F O}

\section{Article Type}

Historical Original Research

\section{Authors}

Karimian A.* MSC
How to cite this article Karimian A. Women's Health Education; Formal Training system of women in Iran before Mashrootiat Revolution till 1298 A.H. that the First School of Midwifery was Founded. Sarem Journal of Reproductive Medicine. 2017; 1(4):171-178.
*Governmental Management Training Center, Tehran, Iran

\section{Correspondence}

Address: Sarem Women's Hospital, Basij Square, Phase 3, Ekbatan Town, Tehran, Iran. Postal Code: 1396956111

Phone: +98 (21) 44670888

Fax: +98 (21) 44670432

ali.karimian1342@gmail.com

\section{Article History}

Received: April 26, 2016

Accepted: October 6, 2016

ePublished: November 15, 2017

\begin{abstract}
A B S T R A C T
Introduction Although with the onset of the activities of clinics in Tehran and major cities mortality was somehow reduced, still treating mother- and child-related diseases was affected by traditional medicine. Therefore, the need to promote general knowledge and modern education to traditional physicians was highly tangible to educated physicians and urged them to take urgent action to resolve this problem. In this way, three main educational approaches were chosen for different target groups: education and public awareness through publishing scientific and health articles in journals, the teaching of traditional physicians through the study of compiled and translated specialized books, and the inclusion of health education courses in elementary education. The author has been able to compile materials about the establishment of new schools and classical education through the materials contained in the archives and libraries of the country, especially the National Library of the National Documentation Center. Conclusion Although a small number of national and state schools were established in Tehran and the center of the states for the education of girls before the Constitutional Revolution (Mashrootiat) with the assistance of the educators of that age, the need to promote the health knowledge, especially the health of mothers and children for educated physicians and midwives was essential. They tried to improve public health knowledge and public awareness of women via the modern education approach through: 1) scientific articles in journals, 2) compilation and translation of books, and 3) public education in schools; in the later years, these trainings lead to the establishment of the Higher School of Midwifery.
\end{abstract}

Keywords Education; Women Health; Traditional Medicine; Preventive Medicine; Midwifery

\section{CITATION LINKS}

[1] The history of military medicine [2] Initiation of IVF in Iran [3] Analytical report of 4 year performance: (on the occasion of the 70th year of establishment of the Terhran University of Medical Sciences 1935-2009) [4] Shokofeh Newspaper [5] Shokofeh Newspaper [6] Shokofeh Newspaper [7] Shokofeh Newspaper [8] Zadolmosaferin, Khergheh Bakhiyeh [9] TalimolGhavabel: Midwifery training in Qajar [10] Glimpses of life and manners in Persia [11] Constitutionalism in Iran [12] Iran Cultural Organization [13] Hamadan education in Iran's modern education system at beginning of the third period in Documents (1927-1993) [14] Modern Schools in Qajar era, Initiatiors and Pioneers [15] Economics of Education during the Pahlavi era [16] Ministry of Education [17] National Library and Archives of Iran. Accession No.297000369 [18] Sending students abroad in the Qajar period [19] National Library and Archives of Iran. Accession No.51008 [20] Some records on girl's schools from constitution to Pahlavi dynasty [21] Iran-e-no [22] Supreme Council meetings [23] The form of talks and meetings of the Supreme Council of the First Segment from 14 July to 72th session in 19 March 1927 [24] History of New Civilization Institutions in Iran [25] Life disasters 
دروس اصلى آموزش در نظر گرفته مىشد. نخستين دوره

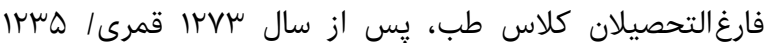

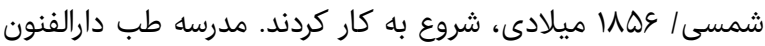

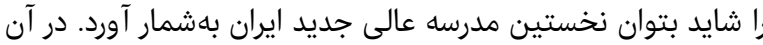

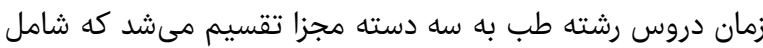

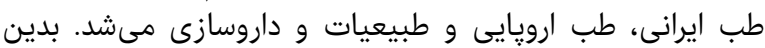

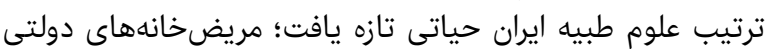
تاسيس شدند و محصلان عملاً با طب جديد آشان ماندا شدند (تصوير ا).

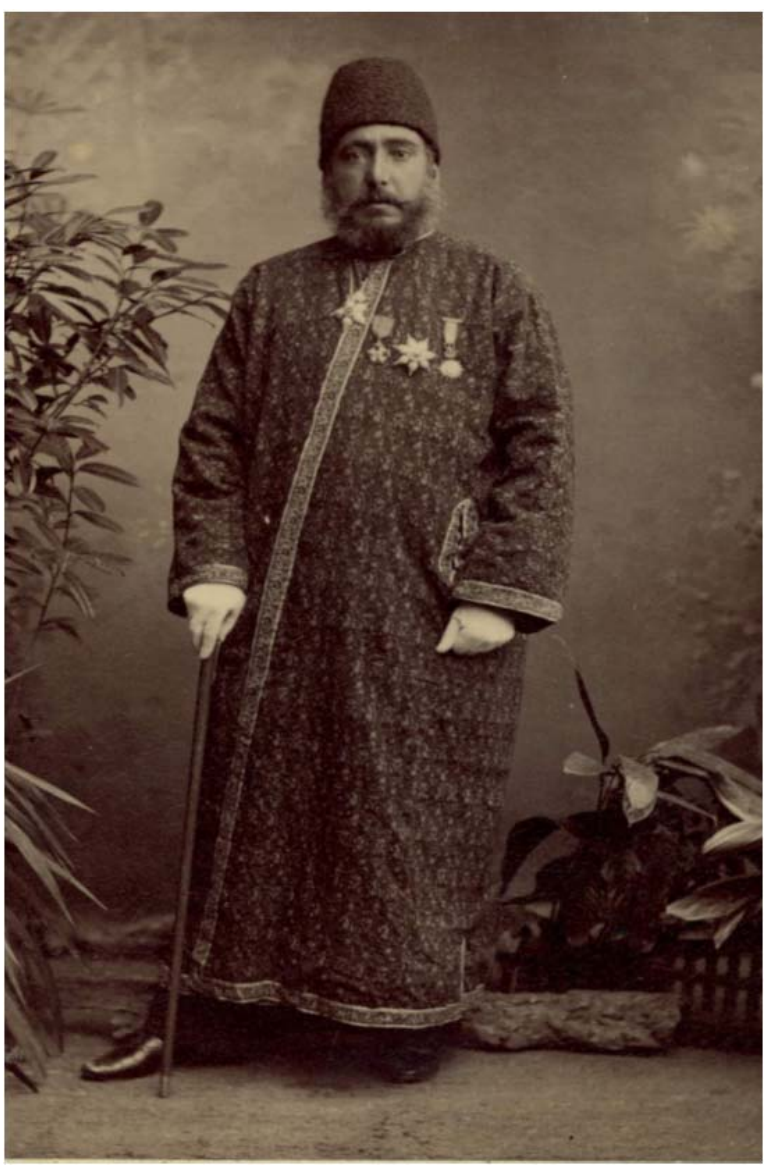

تصوير ) ) تصوير فخرالاطباء از اطباى آشنا با طب ارويايى

شعبهاى براى تربيت قابلهها و طبيبهها در مريض إنانه داير شد،

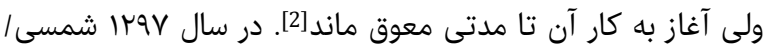

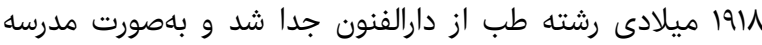

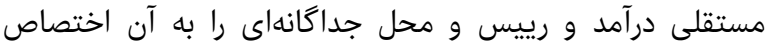

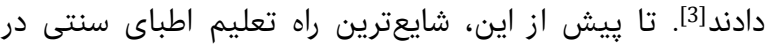

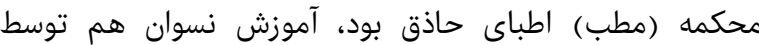

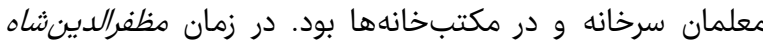

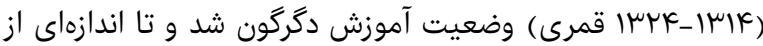

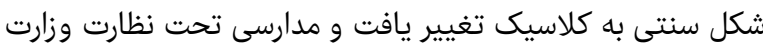

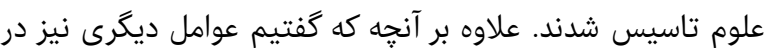

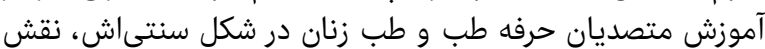

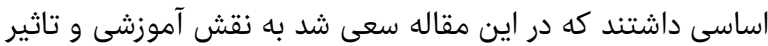

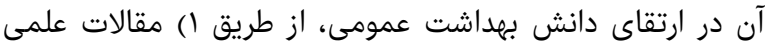

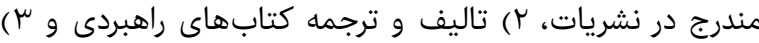

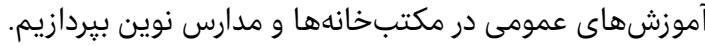

تعليم حفظالصحه نسوان (آموزشهاى رسمى رئان بهداشت و سلامت زنان و دختران) قبل از انقلاب مشروطه تا تاسيس اولين مدرسه قابلكى در سال

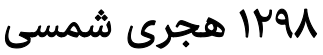

\author{
MSc "على كريميان \\ مركز آموزش مديميان ع عديت دولتى، تهران، ايران
}

جكيده

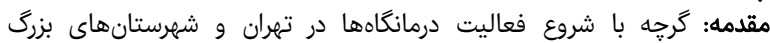

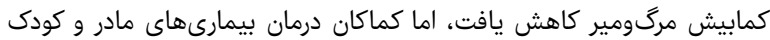

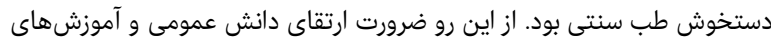

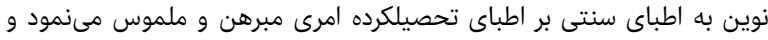

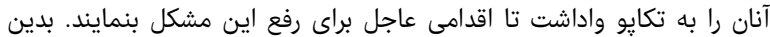

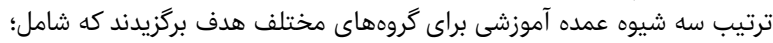

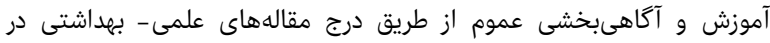

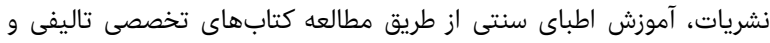

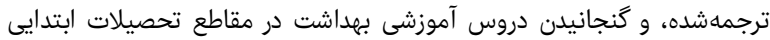

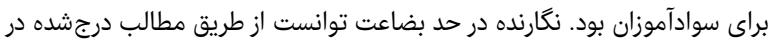

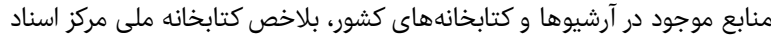

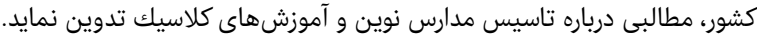

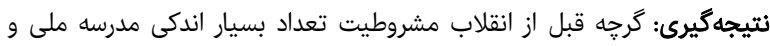

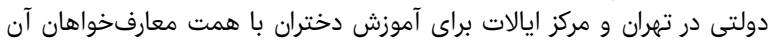

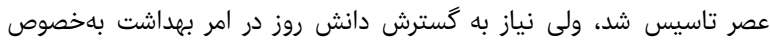

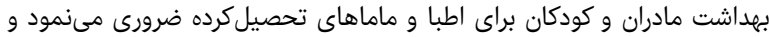

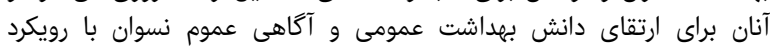

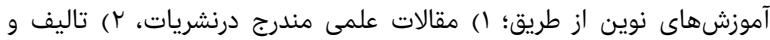

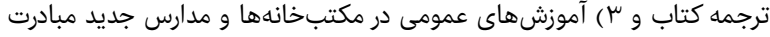

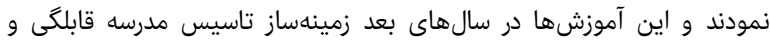

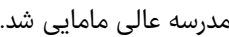
كليدوازهها: آموزش، سلامت زنان، طب سنتى، يزشكى يِيشَّيرى، قابلكَى

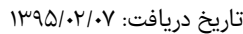

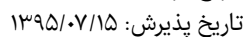

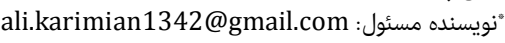

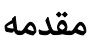

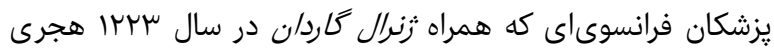

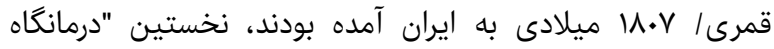

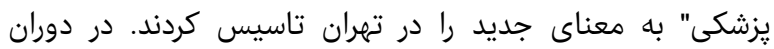

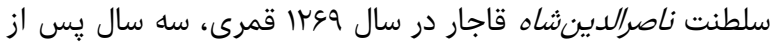

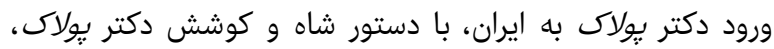

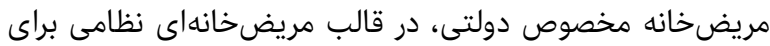

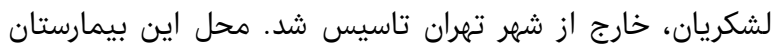

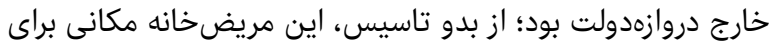

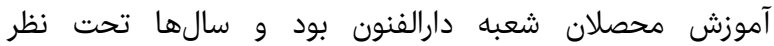

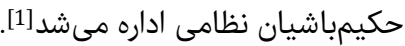

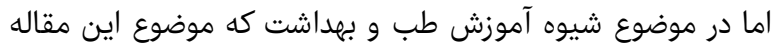

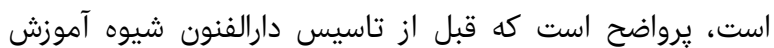

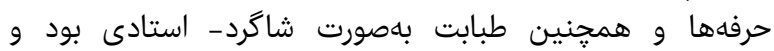

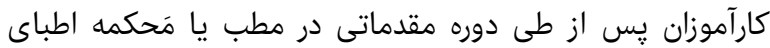

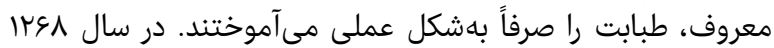

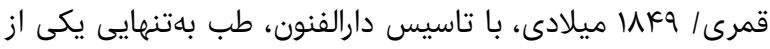

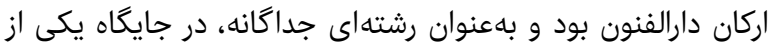


حفظ الصحه خواتين

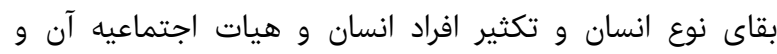

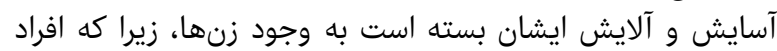

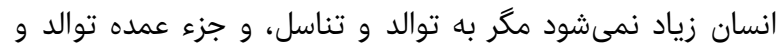

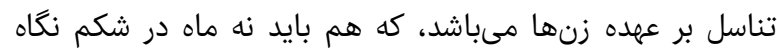

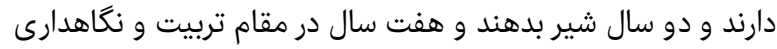

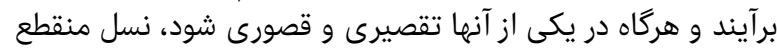

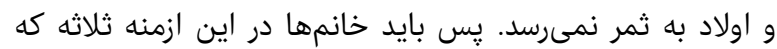

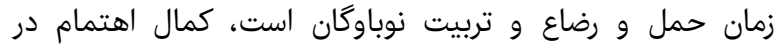

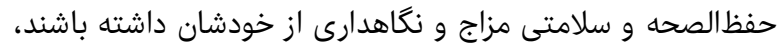

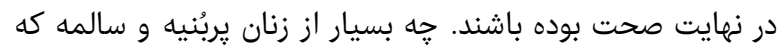

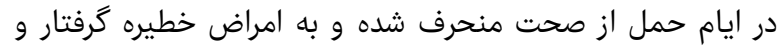

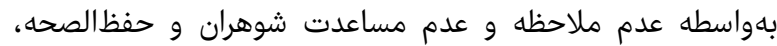

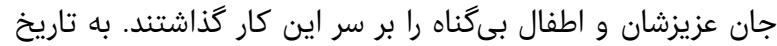

ششم شهر ربيع الاول اسرسا قمرى" [4]؛؛ (تصوير ؟).

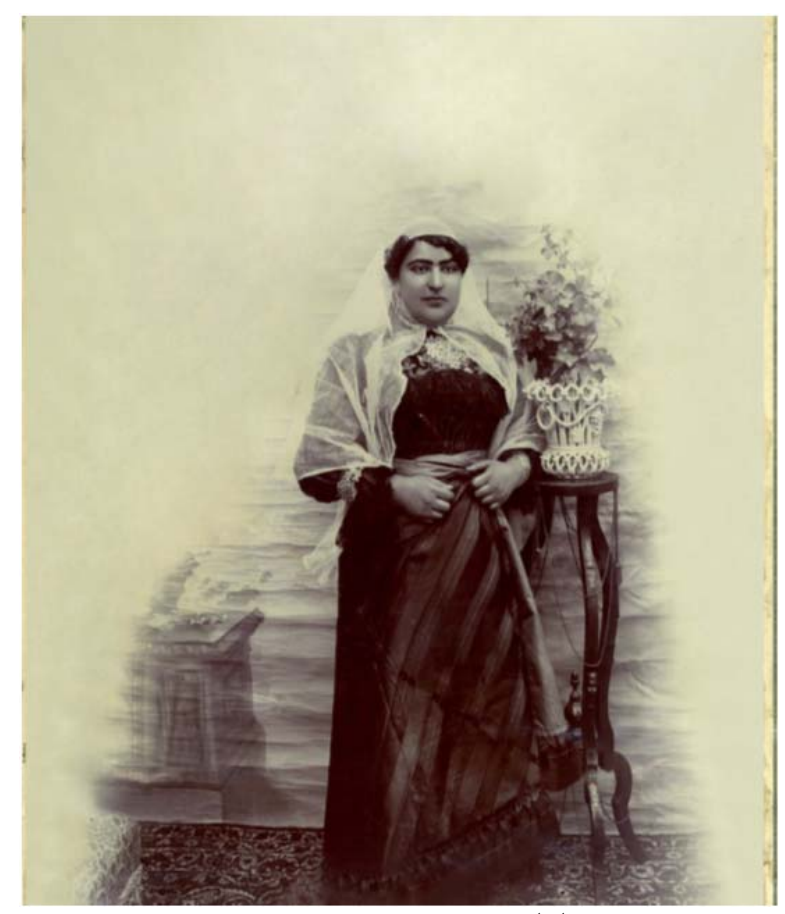

تصويرץ) زن در دوره قاجاريه

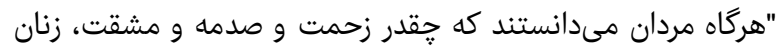

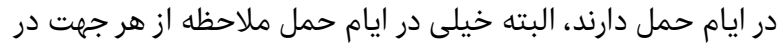

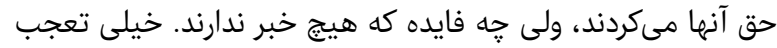

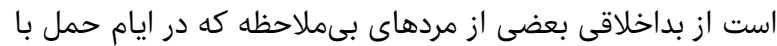

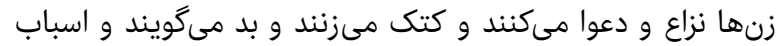

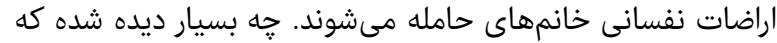

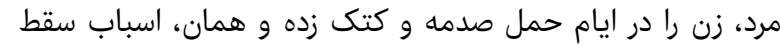

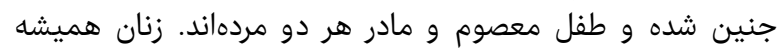

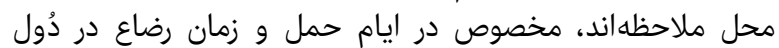

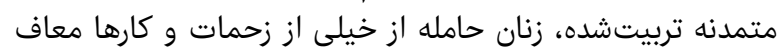

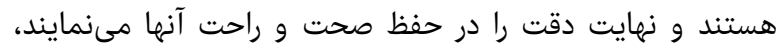

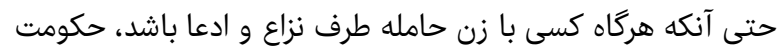

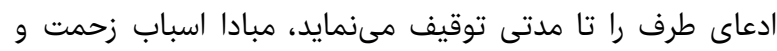

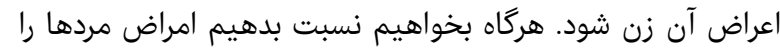

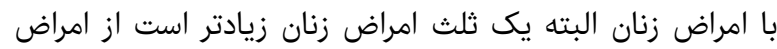

شرح متن

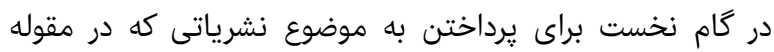

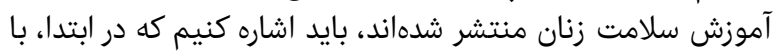

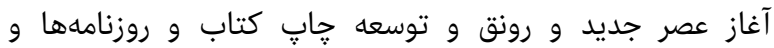

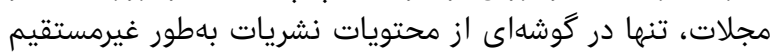

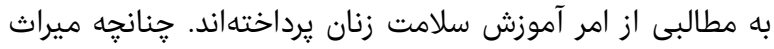

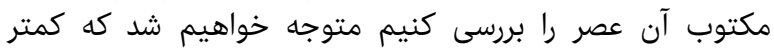

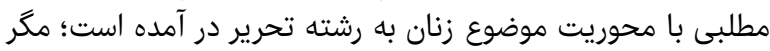

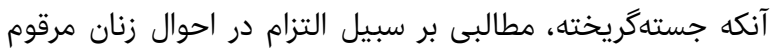

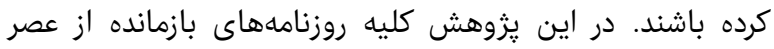

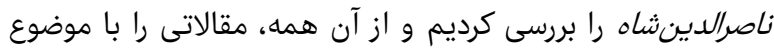

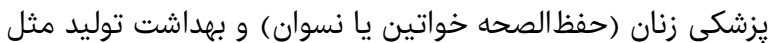

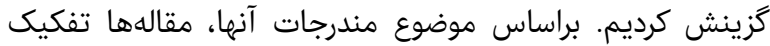

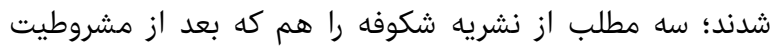
منتشر مى شد، در اين جستار تقرير كرديم. منابع و مدارك ما ما به اين مثرطيت

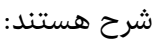

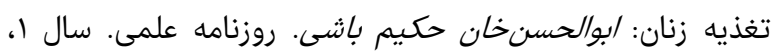

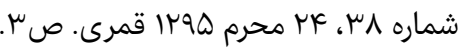

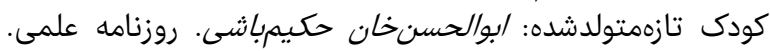

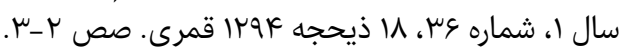

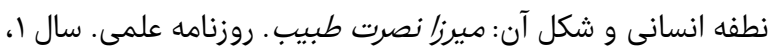

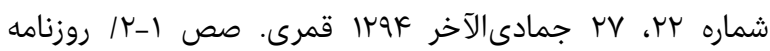

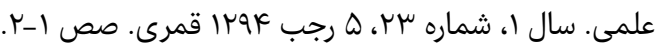

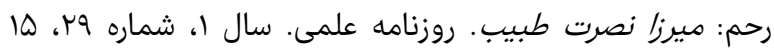

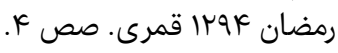

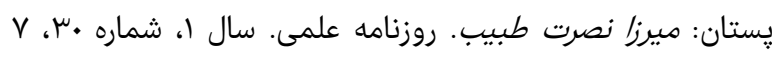

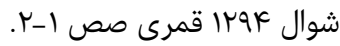

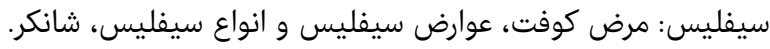

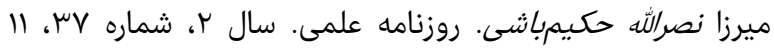

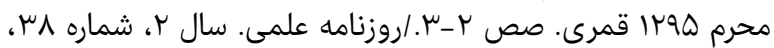

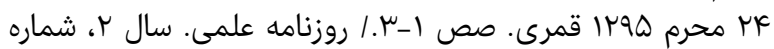

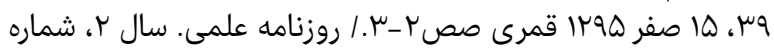

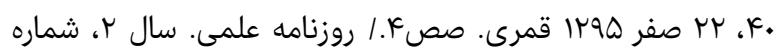

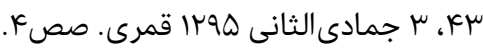

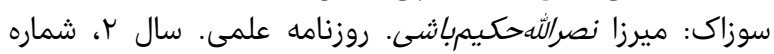

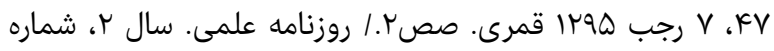

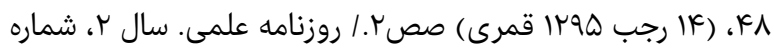

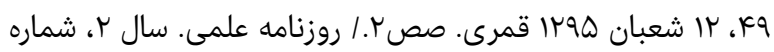

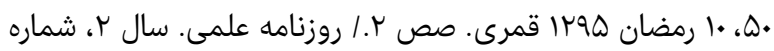

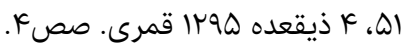

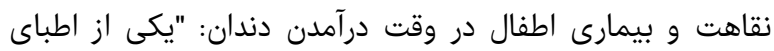

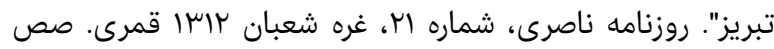

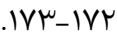

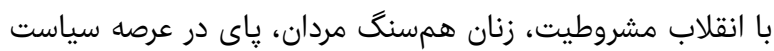

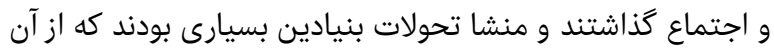

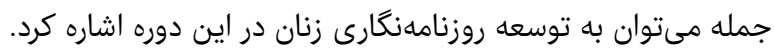

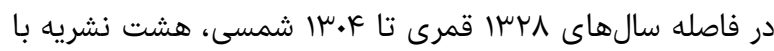

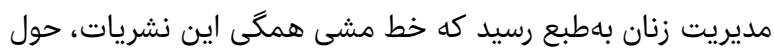

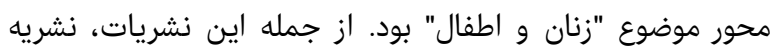

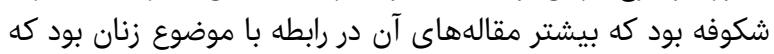

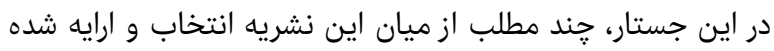


كرده و اين حركت را شبيه به يك نوع برخورد يا احساس به دغدغ رونه

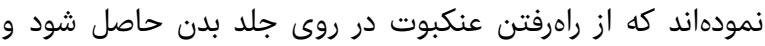

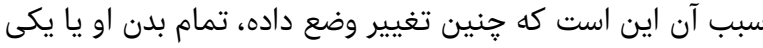

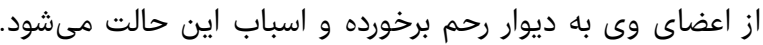

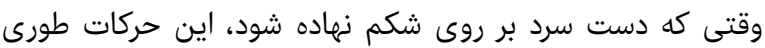

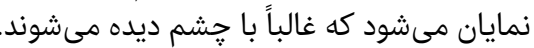

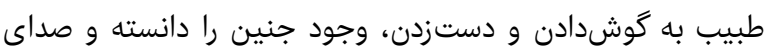

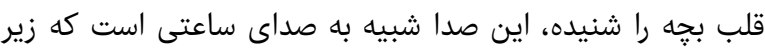

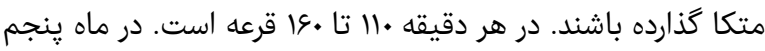

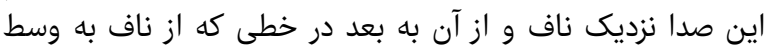

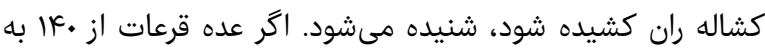

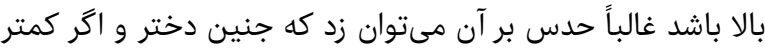

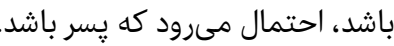

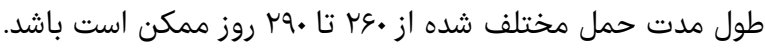

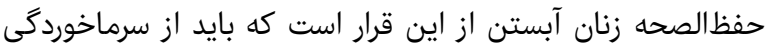

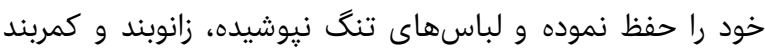

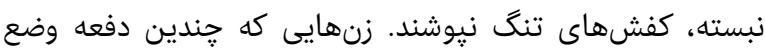

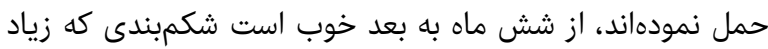

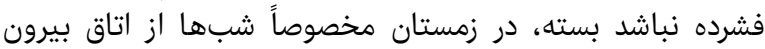

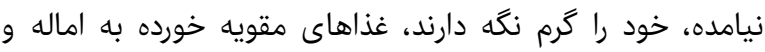

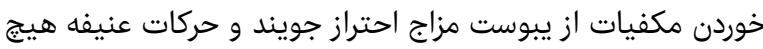

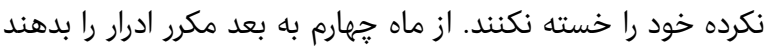

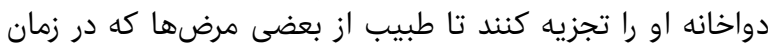

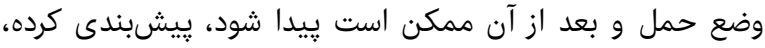

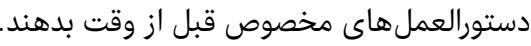

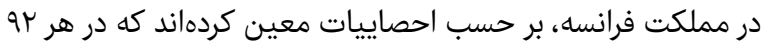

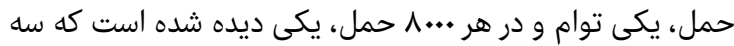

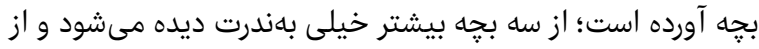

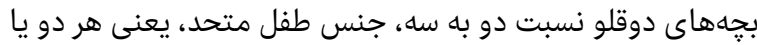

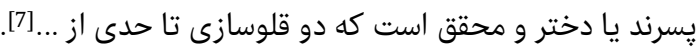

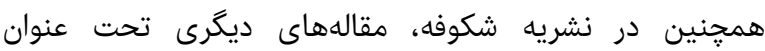

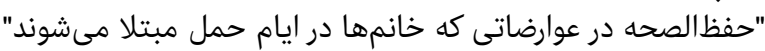

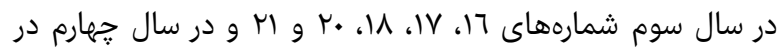
شماره اول نكاشته شده است.

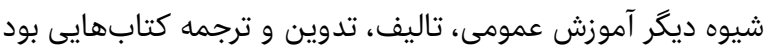

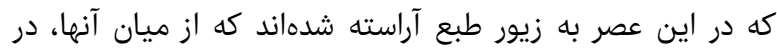
اينجا جند نسخه بهايجاز معرفى مى إشوند:

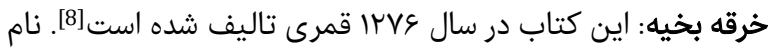

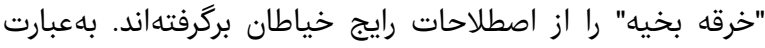

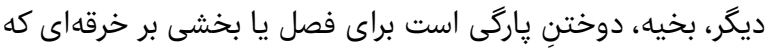

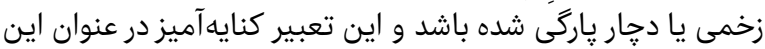
كتاب مورد استفاده قرار كرفته است.

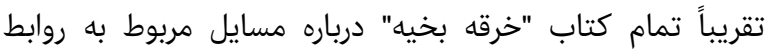

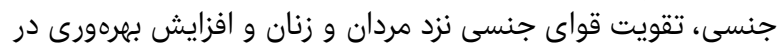

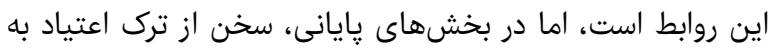

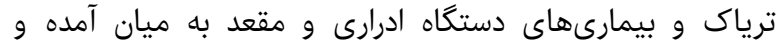

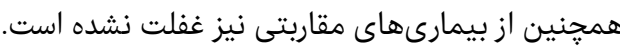

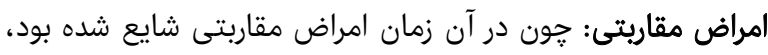

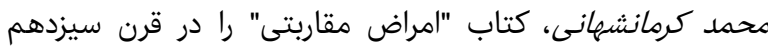

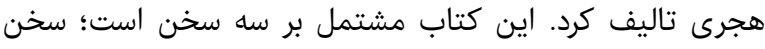

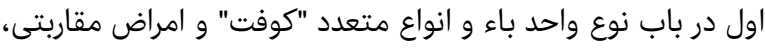
سخن دوم در بيان "كوفت" بهطور عموم و سخن سوم شامل سه أه أه

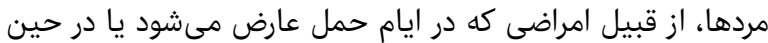

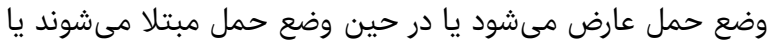

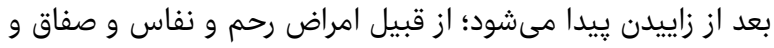

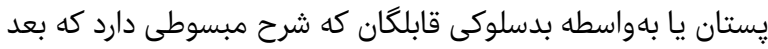

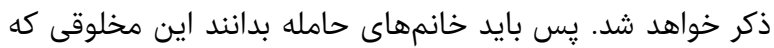

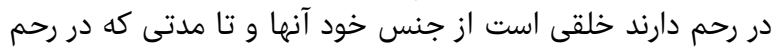

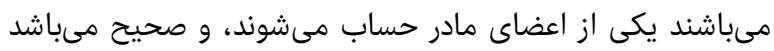

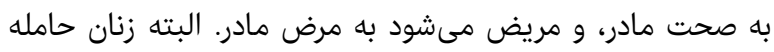

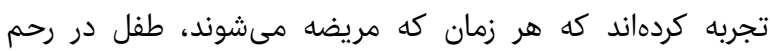

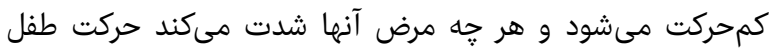

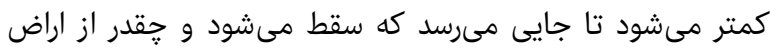

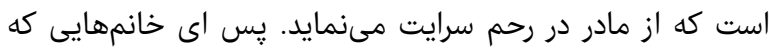

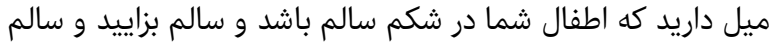

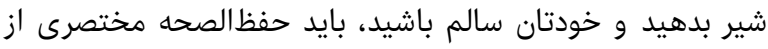

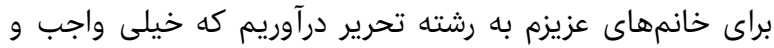

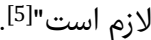
"در سابق ذكر شد كه امراض زنان دو ثلث زيادتر از امراض مردان

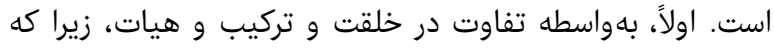

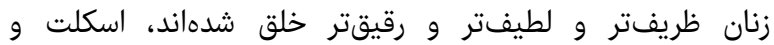

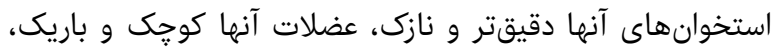

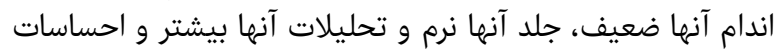

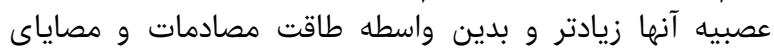

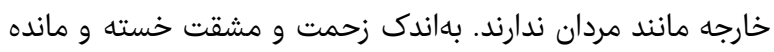

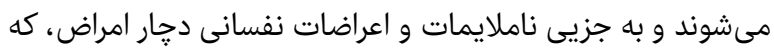

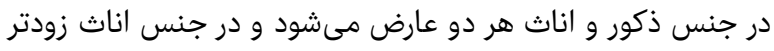

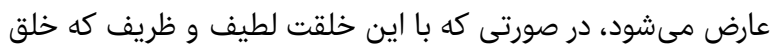

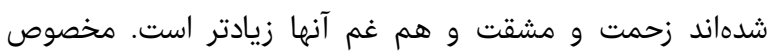

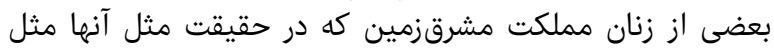

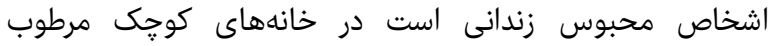

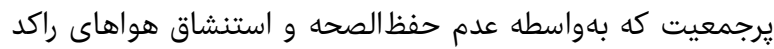

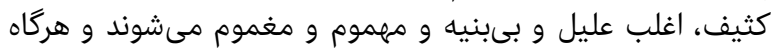
به لطايف و نكات خلقت در نائ نهايت دقت ملات ملاحظه شود، معلوم

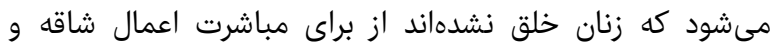

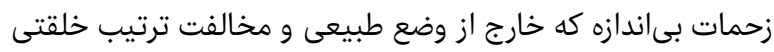

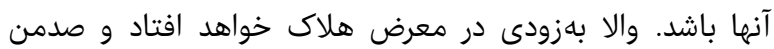

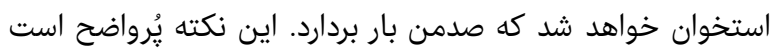

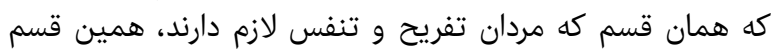

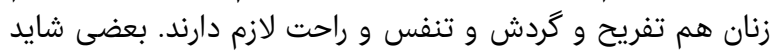

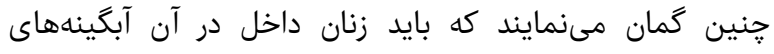

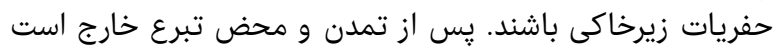

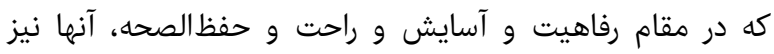

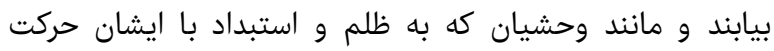

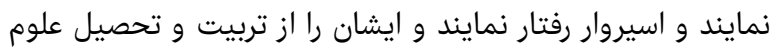

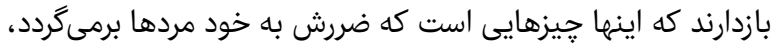

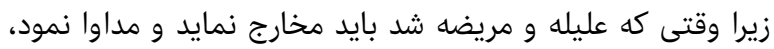

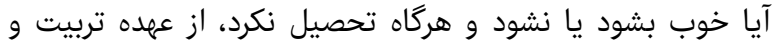

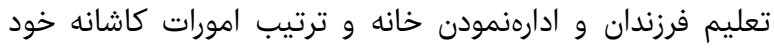

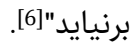
مقالات طبى و حفظالصال الصحه از فرمايشات جناب مستطاب، آقاى اعلمالدوله دامت توفيقاته

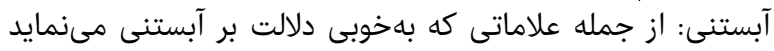

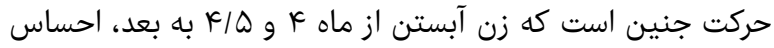




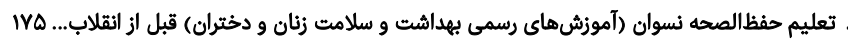

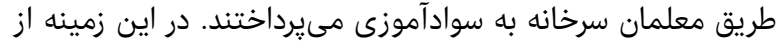

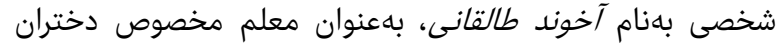
فتحعلىشاه ياد شده است] [10].

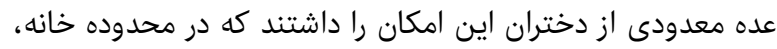

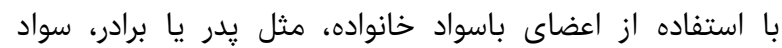

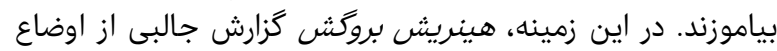

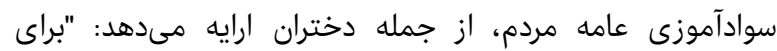

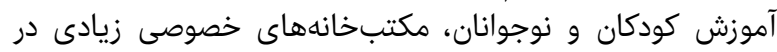

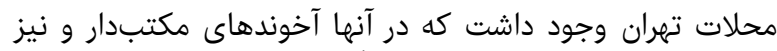

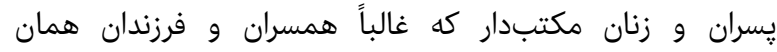

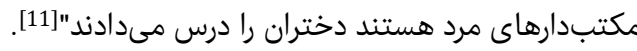

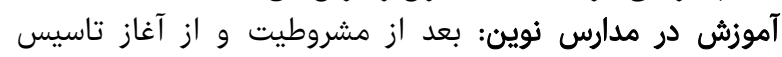

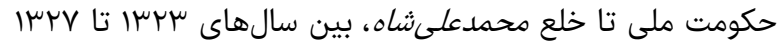

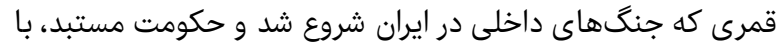

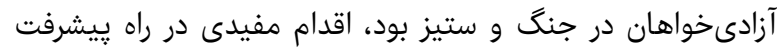

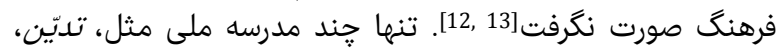

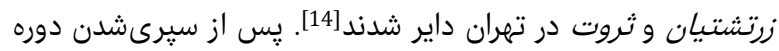

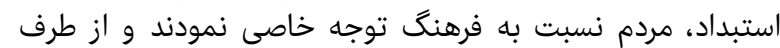

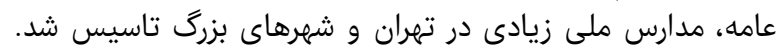

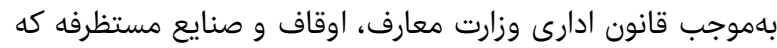

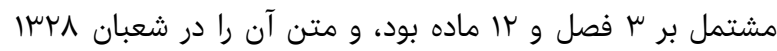

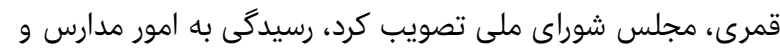

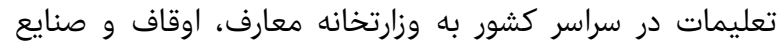
مستظرفه سيرده شد.

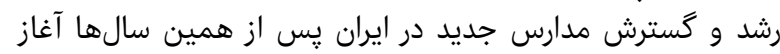

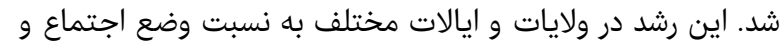

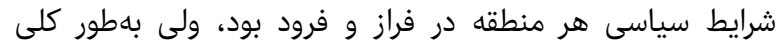

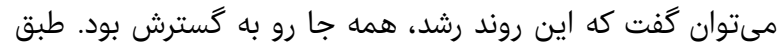

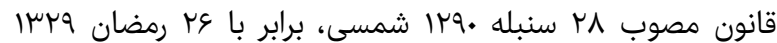

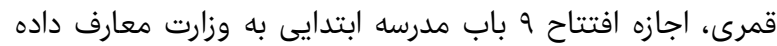

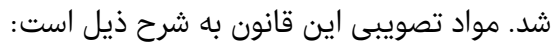

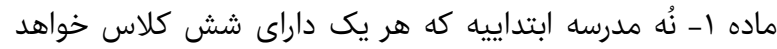

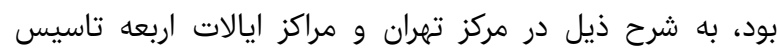

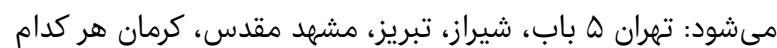
يك باب.

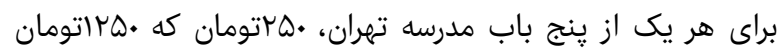

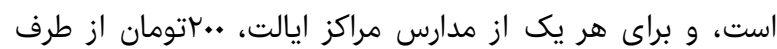

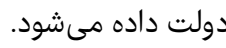

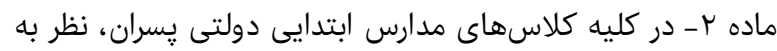

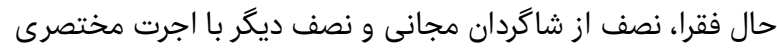

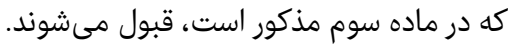

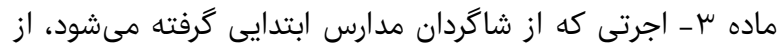

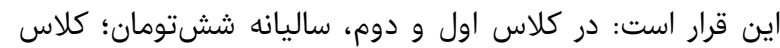

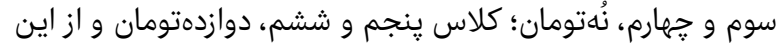

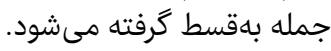

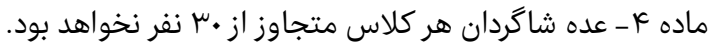

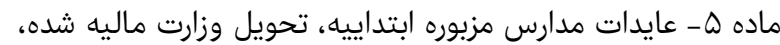

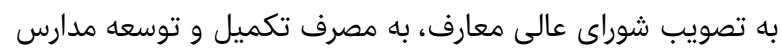
ابتداييه مىرسد.

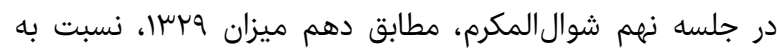

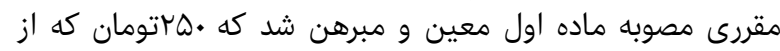

كفتار و يك خاتمه است. گفتار اول مشتمل بر ها فصل، گفتار دوم

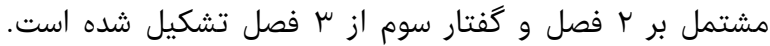

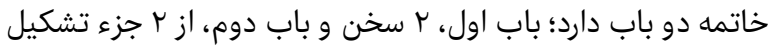

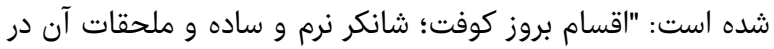

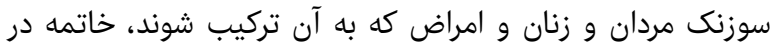

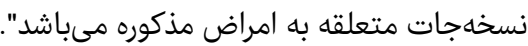

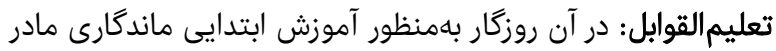

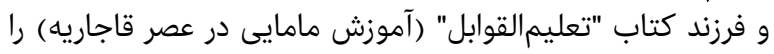

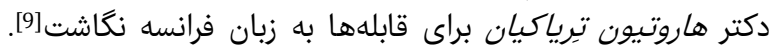

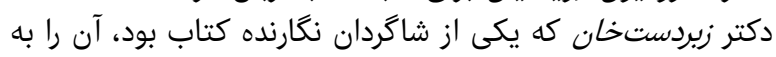

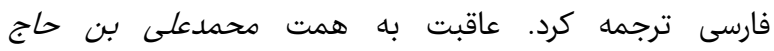

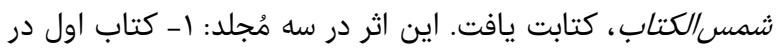

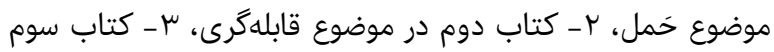

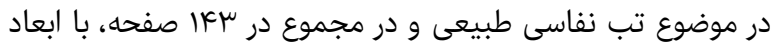

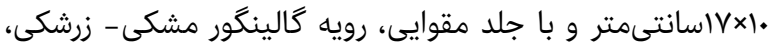

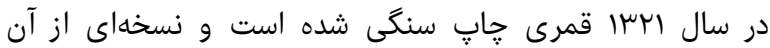
بهشماره PVA99

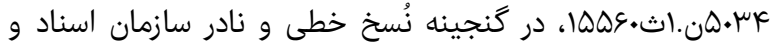

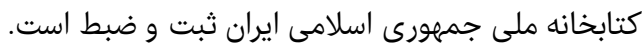

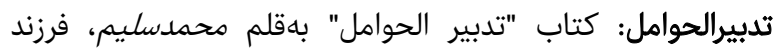

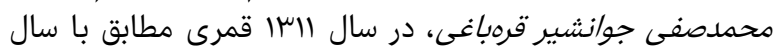

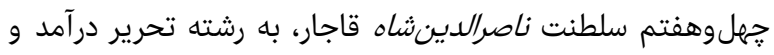

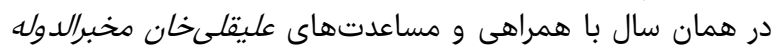

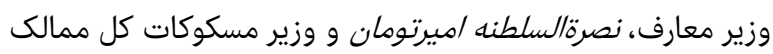

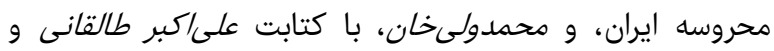

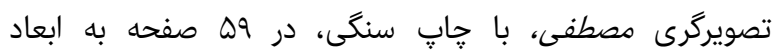

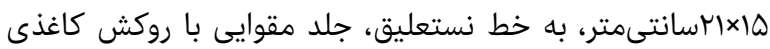

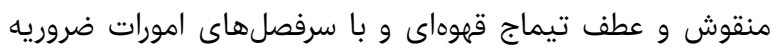

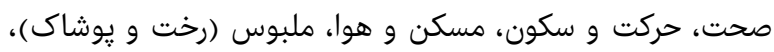

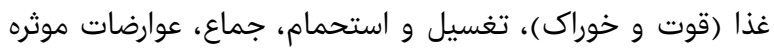

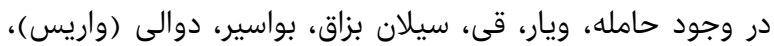

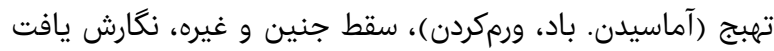

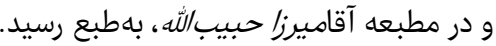

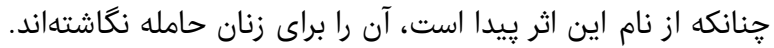

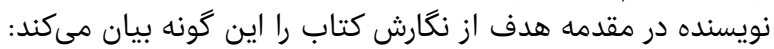

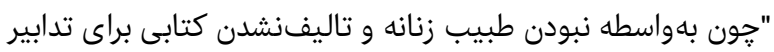

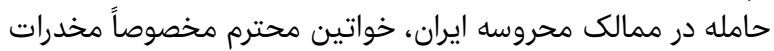

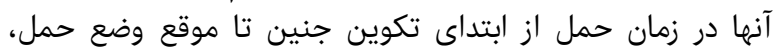

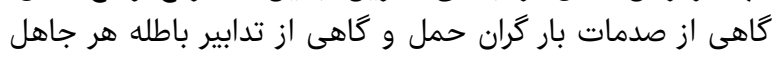

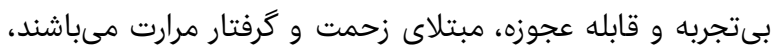

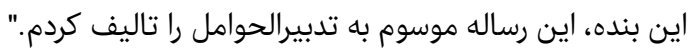

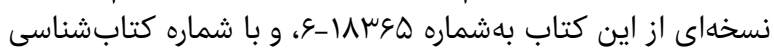

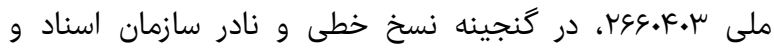

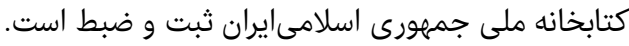

آموزشهاى عمومى در مكتبخانهانها ملى جمان مدارس نوين

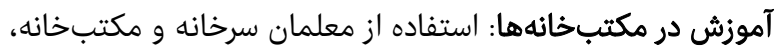

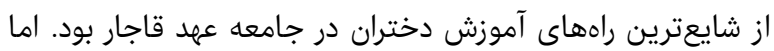

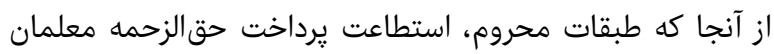

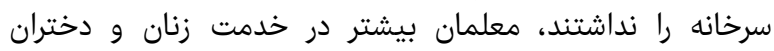

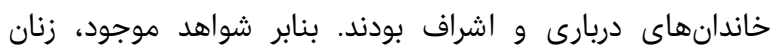

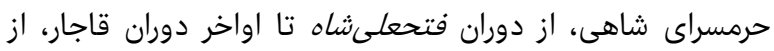


متعددى در اين رابطه نشر يافته است[11].

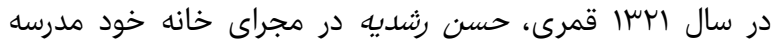

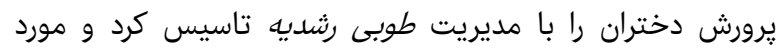

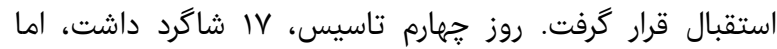
فراشان دولتى تابلو را با فحش و ترفت تهديد برداشتند و مدرسه را راسيس، منحل

در سال ع عبرا قمرى بانو طوبى آزموده به مساعدت و همراهىهاى

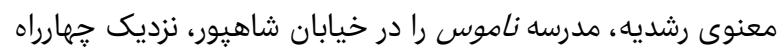

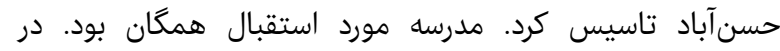

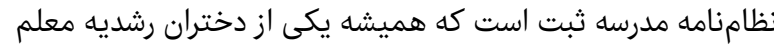
آنها خواهد بود. در سال Vrسا قمرى، مدرسه عفاف در سهراه عودلاجان با مديريت

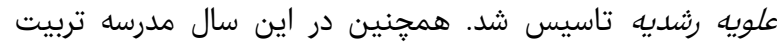

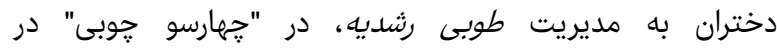

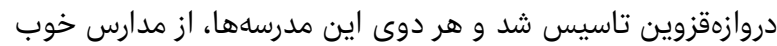
شهر محسوب مى شيدند.

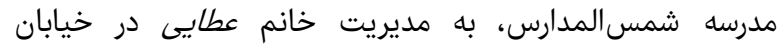

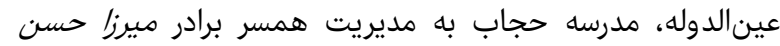

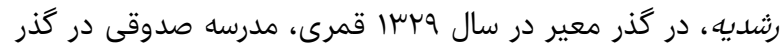

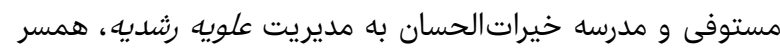

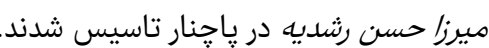

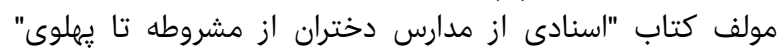

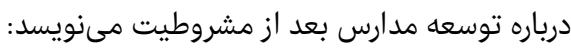

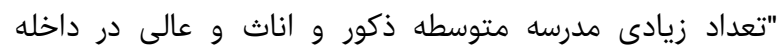

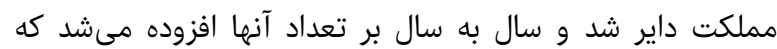

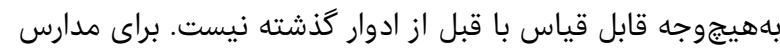

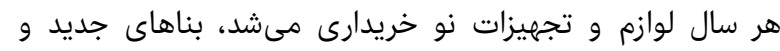

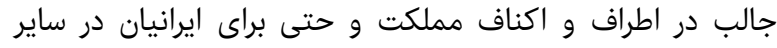

كشورها ساخته شد (تصوير سر).

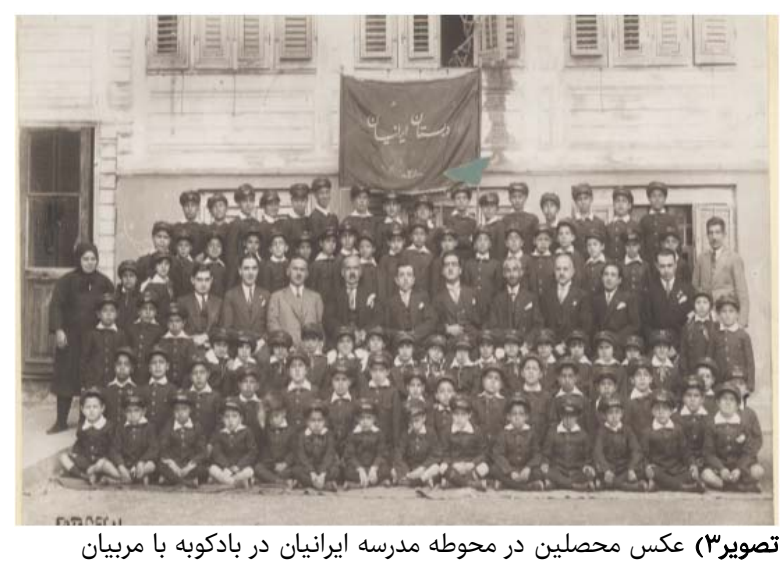

معلمان دانا و بصير استخدام شدند و مدارس عاليه مانند طب و

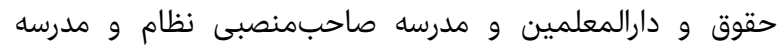

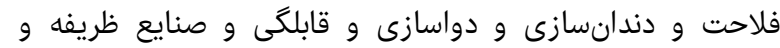

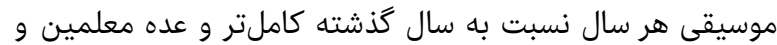

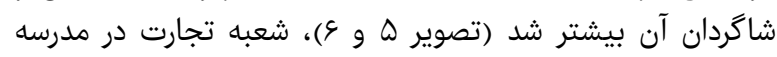

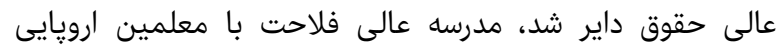

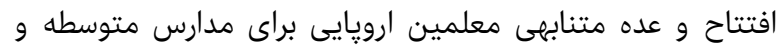
عاليه استخدام شدند"[20].
طرف دولت داده مى شود، ماهيانه است معان [15].

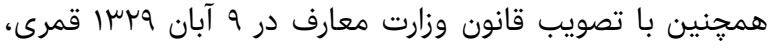

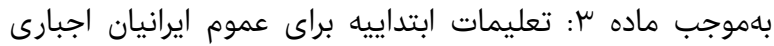

ماده ه: هر كس مكلف است اطفال خود را از سن هفت به تحصيل

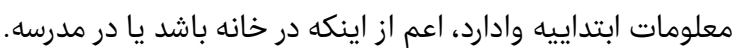

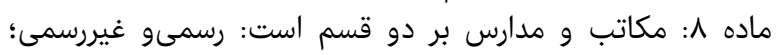

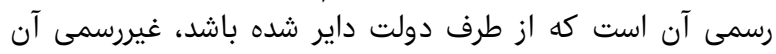
است كه بانى مخصوصى داشته باشد آند [16].

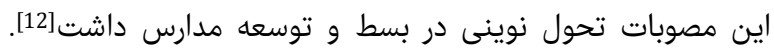

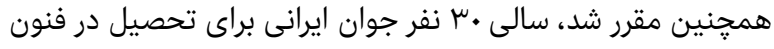

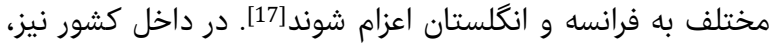

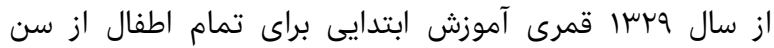

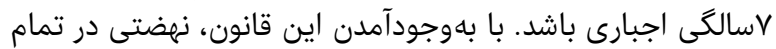

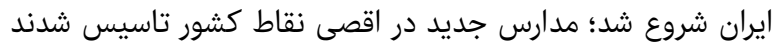

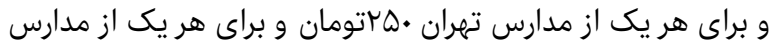

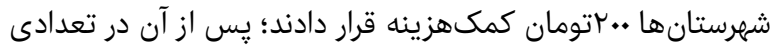

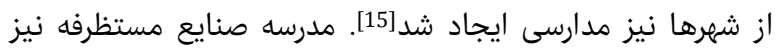

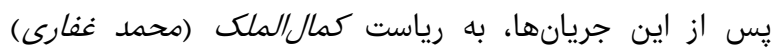

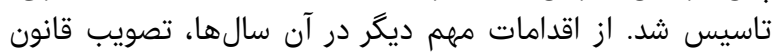

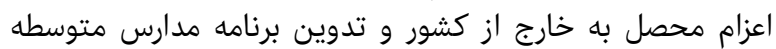
بود [18].

بودجه مدارس: يس از بهثمرنشستن مشروطيت در سال

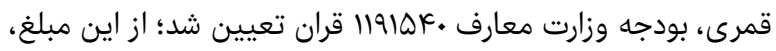

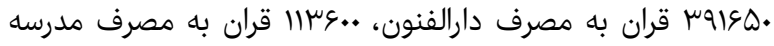

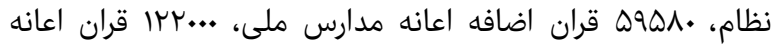

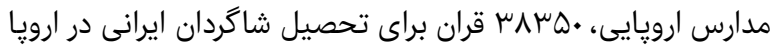

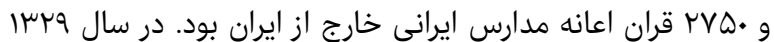

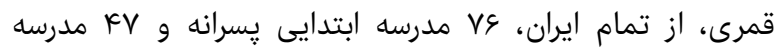

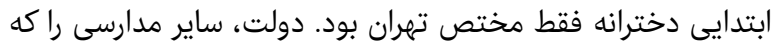

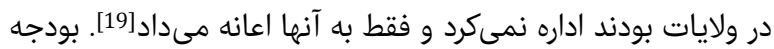

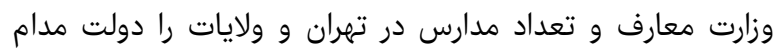

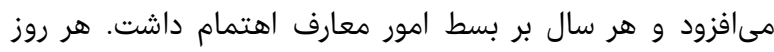

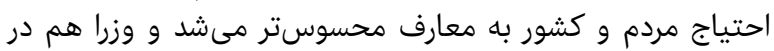

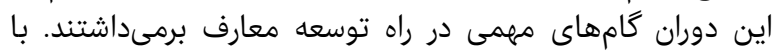
برخاستن اين نهضت، مردم هم بار امكانات ماري شخصى دراه به تاسيس

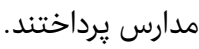

با همه اين اوصاف، عمده ترقى مدارس ايران از سال عسرا قمرى|

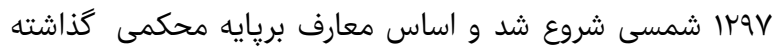

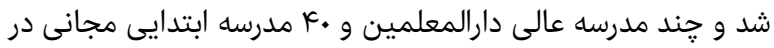

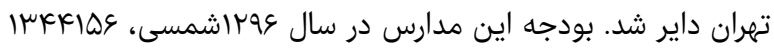

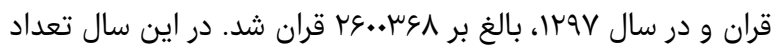

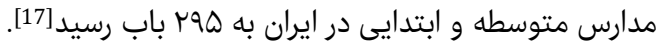

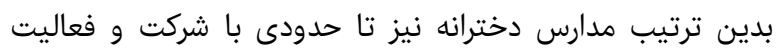

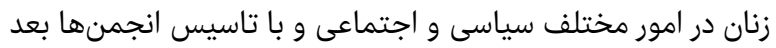

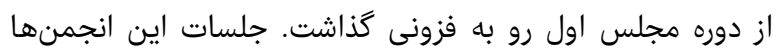

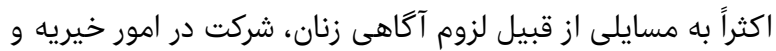

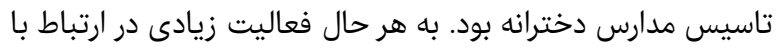

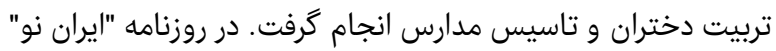

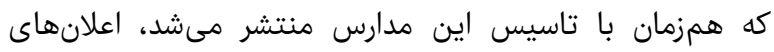




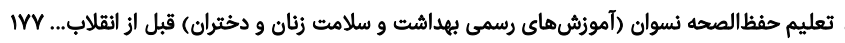

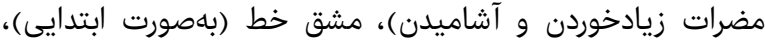

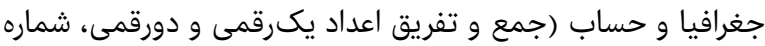

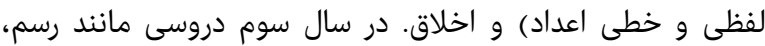

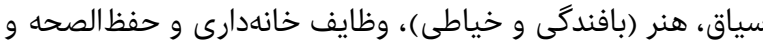

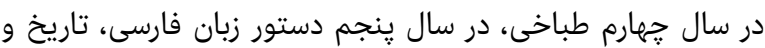

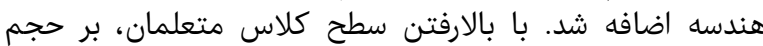

دروس هم افزوده شد[11].

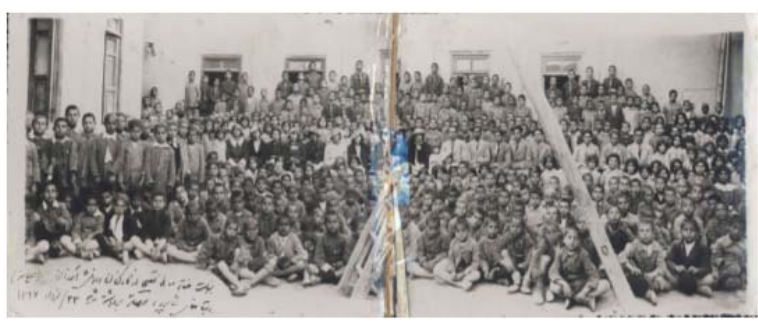

تصوير \&) عكس محصلين شهرستان ميانه در سال IIVI

در سالهاى بعد دروس بهداشت عمومى، در مدارس ملى و دولتى

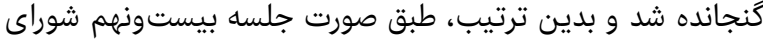

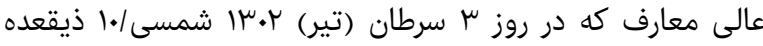

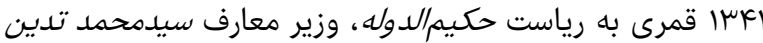

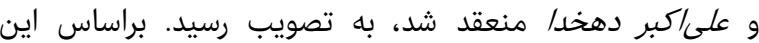

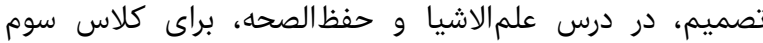

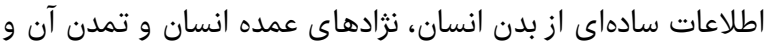

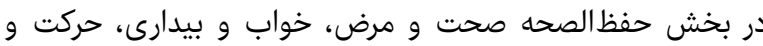

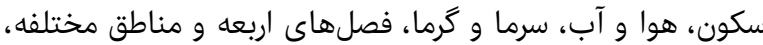

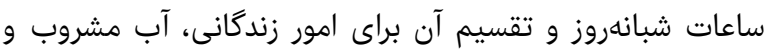

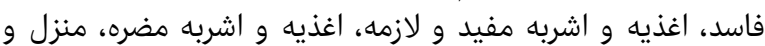

شرايط محل سكنى گنجانده شد [22].

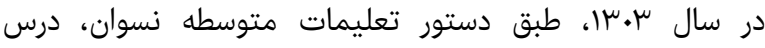

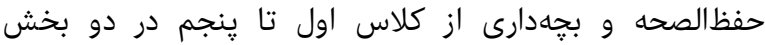

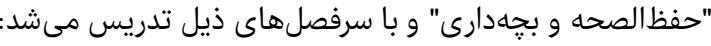

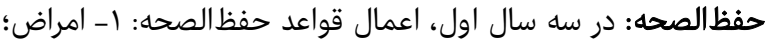

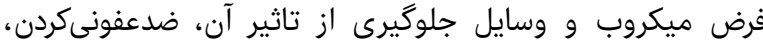

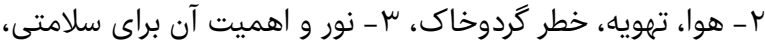

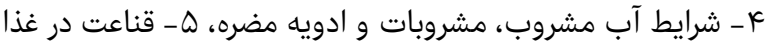

9- نظافت جسمانى بدن و مسكن.

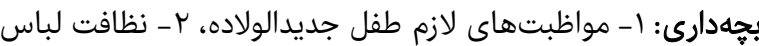

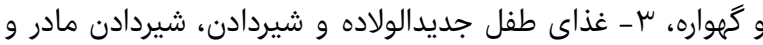

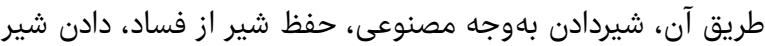

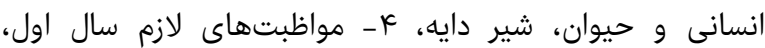

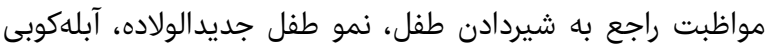

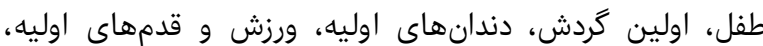

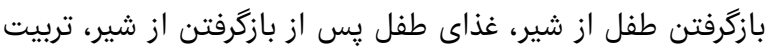

در سال ينجم نيز شاگردان مسنتر تحت نظر معلمات، مطابق

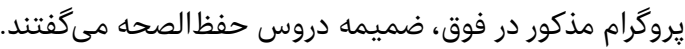

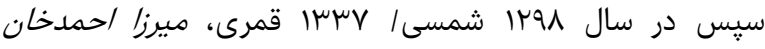

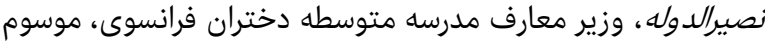

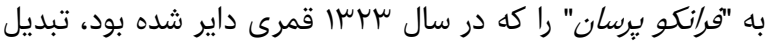

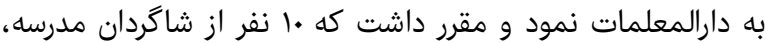

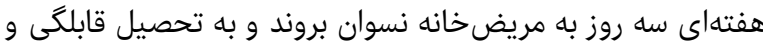

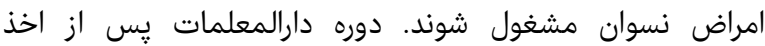

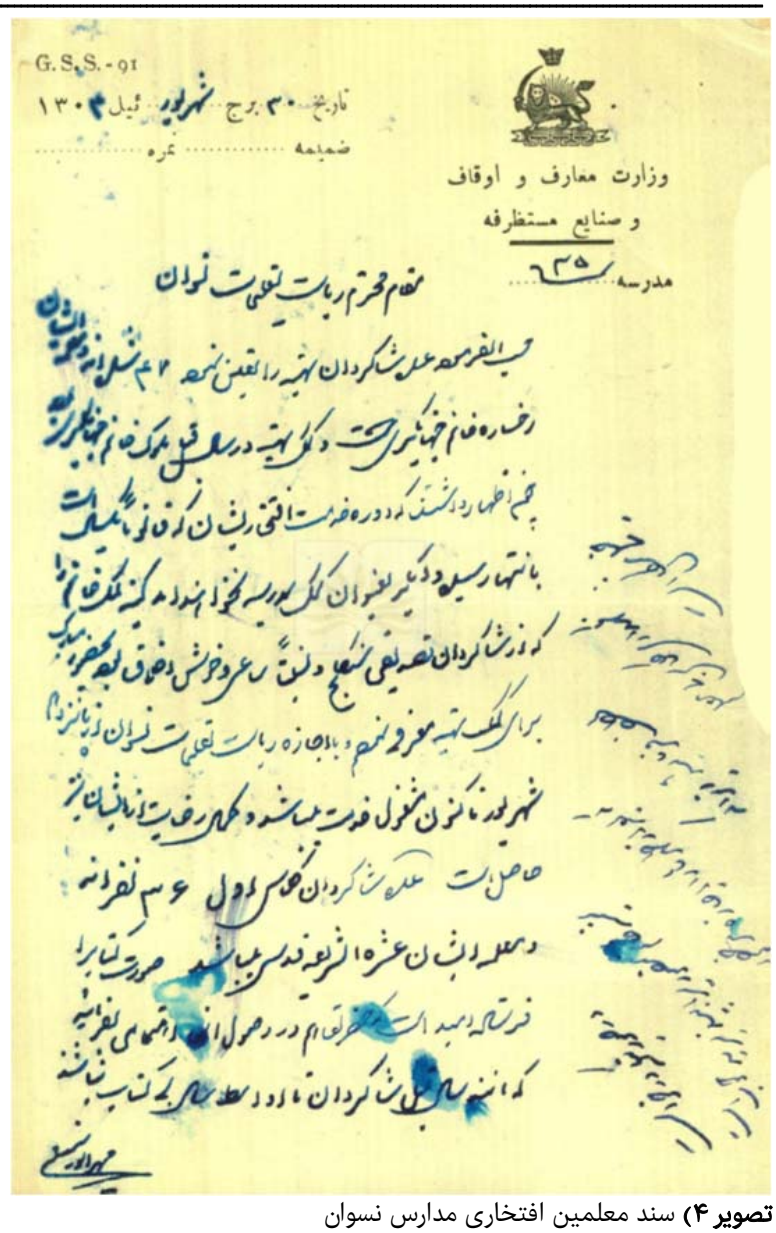

مواد درسى مدارس ابتدايى نسوان: مواد درسى مدارس ابتدايى در

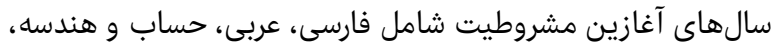

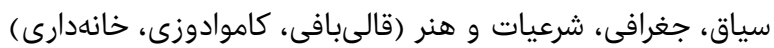

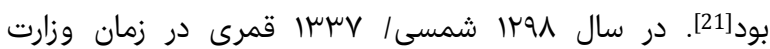

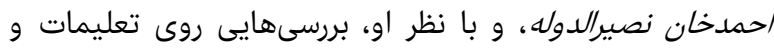
دروس مدارس ابتدايى دختران صورت گرفت (تصوير ه).

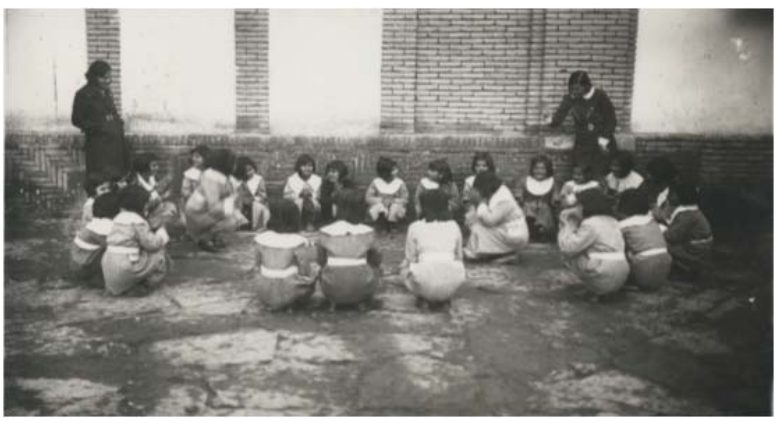

تصوير ه) محصلين يكى از مدارس دخترانه

يس از تجديد نظر، قرار بر اين شد كه اداره كل معارف، تدريس

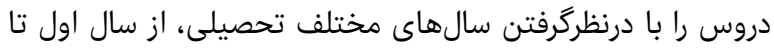

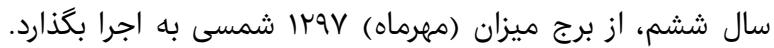

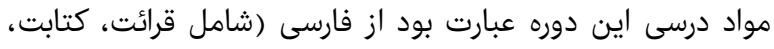

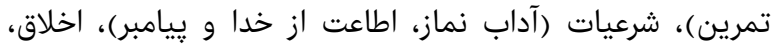

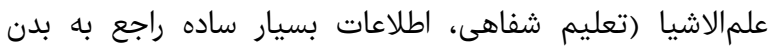

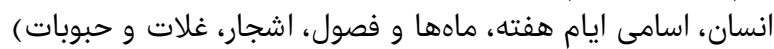

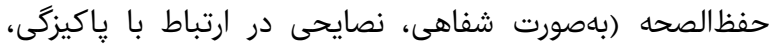


6- Mozayyanosaltaneh M. Shokofeh Newspaper. 1952 ;1(8):2. [Persian]

7- Alamodoleh A. Shokofeh Newspaper. 1954;3(6):4. [Persian]

8- Alinaghi-Sharif MMI, Shamloo MG. Zadolmosaferin, Khergheh Bakhiyeh. Tehran: Research Institute for Islamic and Complementary Medicine; 2003. 287p. [Persian]

9- Taryakian H. TalimolGhavabel: Midwifery training in Qajar. Tehran: Sarem Book; 2014. p.94. [Persian]

10- Sheil MLW. Glimpses of life and manners in Persia. Aboutorabian H, translator.Tehran: Nashre No; 1989. 279p. [Persian]

11- Takmil Homayoon N. constitutionalism in Iran. Tehran: Baz; 2004. p. 374. [Persian]

12- Kani A. Iran Cultural Organization. Tehran: Tehran Universiti Press. 1954. p. 20. [Persian]

13- Teymorifard A, Rahimi M. Hamadan education in Iran's modern education system at beginning of the third period in Documents (1927-1993). Hamadan: West Management National Archives of Iran; 1994. p. 11. [Persian]

14- GhasemiPoya E. Modern Schools in Qajar era, Initiatiors and Pioneers. Tehran: Markaze Nashre danshgahi; 1998. p.237. [Persian]

15- Birshak A, Zamani M. Economics of Education during the Pahlavi era. Tehran: Anonymous Publisher; 1976. pp. 12-3. [Persian]

16- Hekmat AA. Ministry of Education. In: Iranshahr. Unesco-Iran, Iran-shahr; a survey of Iran's Land, people, culture, gverment and economey. 2th volume. Tehran: National Commission of UNESCO; 1963. p.1171. [Persian] 17- National Library and Archives of Iran. Accession No.297000369. Tehran: National Library and Archives of Iran. [Persian]

18- Sarmad GA. Sending students abroad in the Qajar period. Tehran: Bonyad; 1993. p. 104. [Persian]

19- National Library and Archives of Iran. Accession No.51008.Tehran: National Library and Archives of Iran. [Persian]

20- Torabi Farsani S. Some records on girl's schools from constitution to Pahlavi dynasty. Tehran: National Library and Archives of Iran; 1999. p. 227. [Persian]

21- Anonymous writer. Iran-e-no. 1910 Jan 19. 1(114). p. 4. [Persian]

22- Supreme Council meetings. 1883-1884. [Persian]

23- The form of talks and meetings of the Supreme Council of the First Segment from 14 July to 72th session in 19 March 1927. [Persian]

24- Mahbobi Ardekani H. History of New Civilization Institutions in Iran. Tehran: Tehran University Press; 1992. pp. 416-7. [Persian]

25- Roshdiyeh S. Life disasters. Tehran: Tarikhe Iran Publication; 1984. p.148. [Persian]
تصديقنامه ششرساله ابتدايى، جهار سال بود كه سه سال اول

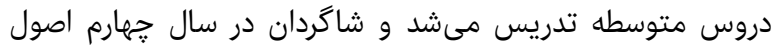

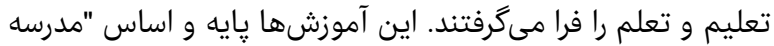

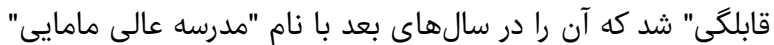

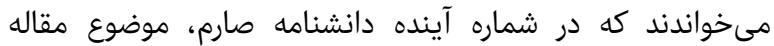
ديكرى خواهد بود.

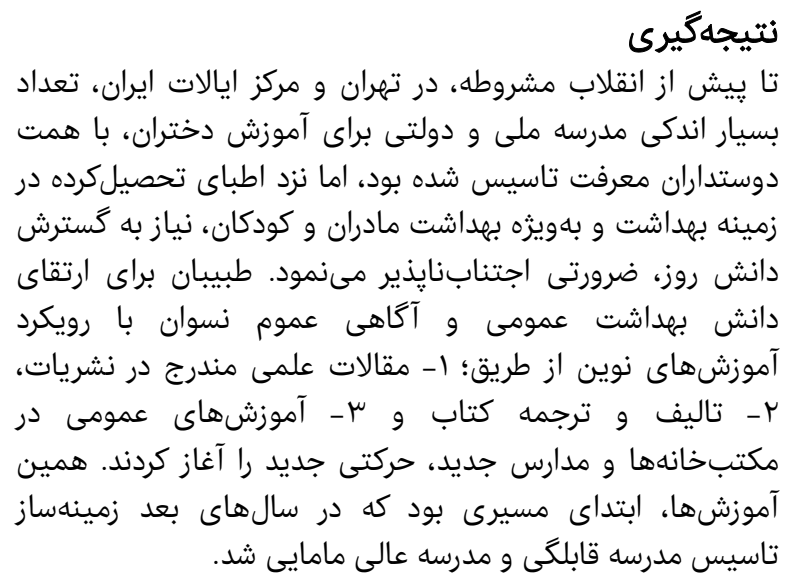

تشكر و قدردانى: نكارنده از همكارى صميمانه سركار خانمها/نسيه

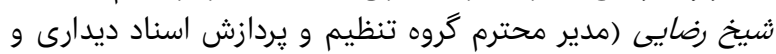

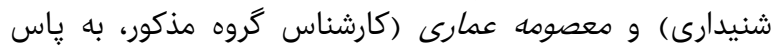

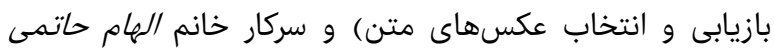

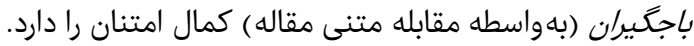

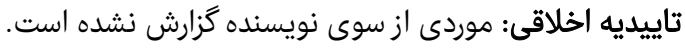

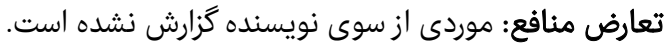

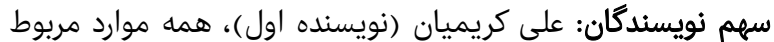

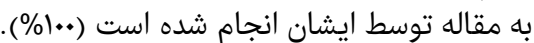

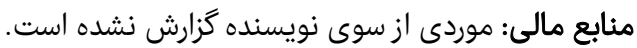

\section{منابع}

1- Namjooynik K. The history of military medicine. Tehran: Iran-e-Sabz; 2009. p.78. [Persian]

2- Saremi A. Initiation of IVF in Iran. Tehran: Sarem Book; 2014. p.20. [Persian]

3- Tehran University of Medical Sciences. Analytical report of 4 year performance: (on the occasion of the 70th year of establishment of the Terhran University of Medical Sciences 1935-2009). Tehran: Tehran University Press; 2009. pp. 17-8. [Persian]

4- Mozayyanosaltaneh M. Shokofeh Newspaper. 1952;1(4):3. [Persian]

5- Mozayyanosaltaneh M. Shokofeh Newspaper. 1952;1(5):2. [Persian] 